\title{
Heritabilities and Correlations Among Body Condition Score, Dairy Form and Selected Linear Type Traits
}

\author{
C. D. Dechow, ${ }^{\star}$ G. W. Rogers, ${ }^{\star}$ L. Klei†, and T. J. Lawlor† \\ *Dept. of Animal Science, \\ University of Tennessee, \\ 2640 Morgan Circle, \\ Knoxville, TN 37996 \\ †Holstein Association USA Inc., \\ 1 Holstein Place, \\ Brattleboro, VT 05302
}

\begin{abstract}
The objectives of this study were to estimate the heritability of body condition score (BCS) with data that could be used to generate genetic evaluations for BCS in the US, and to estimate the relationship among BCS, dairy form and selected type traits. Body condition score and linear type trait records were obtained from Holstein Association USA Inc. Because BCS was a new trait for classifiers, scoring distribution and accuracy was not normal. Records from 11 of 29 classifiers were eliminated to generate a data set that should represent BCS data recorded in the future. Edited data included 128,478 records for analysis of first lactation cows and 207,149 records for analysis of all cows. Heritabilities and correlations were estimated with ASREML using sire models. Models included age at calving nested within lactation, 5th order polynomials of DIM, fixed herd-classification visit effects and random sire and error. Genetic correlation estimates were generated between first lactation data that had records from 11 classifiers removed and data with no classifiers removed. Genetic correlation estimates were 0.995 and above between data with and without classifiers removed for scoring distributions, but heritability estimates were higher with the classifiers edited from the data. Heritability estimates for type traits and final score were similar to previously reported estimates. The heritability estimate for BCS was 0.19 for first lactation cows and 0.22 for all cows. The genetic correlation estimate for first lactation cows between BCS and dairy form was -0.73 , whereas the genetic correlation estimate between BCS and strength was 0.72. Genetic correlation estimates were nearly identical when cows from all lactations were included in the analyses. Body condition
\end{abstract}

Received August 9, 2002.

Accepted November 27, 2002. edu. score had a genetic correlation with final score closer to zero (0.08) than correlations of final score with dairy form, stature or strength.

(Key Words: body condition score, heritability, genetic correlation)

Abbreviation key: HD_CL = herd-classification visit.

\section{INRODUCTION}

BCS evaluations may be useful as an indicator trait in selection for improved reproductive performance and cow health. Body condition scores are genetically correlated with improved reproductive performance after adjustment for milk yield (Dechow et al., 2001; Veerkamp et al., 2001; Pryce et al., 2000). Moreover, higher dairy form is genetically correlated with an increase in disease incidence (Rogers et al., 1999; Hansen et al., 2002). Genetic correlation estimates between angularity (a similar trait to US dairy form) and BCS range from -0.47 to -0.77 (Veerkamp and Brotherstone, 1997).

Heritability estimates for BCS when recorded during routine on farm linear type appraisal range from 0.25 to 0.38 in Europe (Pryce et al., 2000; Koenen et al., 2001; Veerkamp et al., 2001). Heritability estimates for BCS in the US have been generated with field data and are lower ( 0.07 to 0.20$)$ than heritability estimates from other studies (Dechow et al., 2001). While studies with field data have helped estimate the genetic relationship among BCS, production and reproductive performance in the US, national genetic evaluations for BCS are not likely to be generated with such data. The Holstein Association USA Inc. began to record BCS during routine linear type evaluations in the fall of 1997 is the probable source of any national genetic evaluations for BCS in the US.

The objectives of this study were to estimate the heritability of BCS with data that could be used to generate genetic evaluations for BCS in the US, and to estimate the relationship among BCS, dairy form and selected type traits. 


\section{MATERIALS AND METHODS}

\section{Data and Editing}

Records for BCS and type traits were obtained from Holstein Association USA Inc., which began recording BCS in the fall of 1997. Therefore, records from October of 1997 through June of 2000 were available. The initial data set included 728,597 records from 613,338 cows. Body condition scores are recorded on a scale of 1 (thin) to 50 (fat) to be consistent with the scale used for linear type traits.

Body condition score distributions were not normal for some classifiers. Scoring procedures for BCS will improve in the future as classifiers become accustomed to evaluating BCS. Therefore, two edits were applied to generate a BCS data set that would represent data used to generate genetic evaluations for BCS in the future.

The standard deviation of BCS in first lactation was 6.37. Therefore, the random number generator in Excel 2000 (Microsoft, Seattle WA) was used to generate 10,000 observations for a trait with a mean of 25 and standard deviation of 6 . The most frequent number generated occurred $6.7 \%$ of the time. However, it is possible to use a limited number of scores when evaluating body condition and still determine differences in body condition among cows accurately. For example, body condition in some European type classification systems is scored on an integer scale of 1 to 9 (Pryce et al., 2000; Koenen et al., 2001; Veerkamp et al., 2001). Therefore, randomly generated scores were grouped in intervals of five, resulting in 10 interval groups. Randomly generated scores fell in the most frequent interval $30.1 \%$ of the time. Data from 10 classifiers that assigned a single BCS more than and $30.1 \%$ of the time for first lactation cows was eliminated.

A second set of classifier edits was applied using the approach of Veerkamp et al. (2002) to identify classifiers that were scoring traits inconsistently when compared with other classifiers. Genetic correlations between BCS recorded by a single classifier and BCS recorded by all other classifiers were generated. Low genetic correlations would indicate that classifier is scoring body condition inconsistent with other classifiers. Veerkamp et al. (2002) reported genetic correlations for BCS between a single classifier and BCS for all other classifiers to be greater than 0.92 for classifiers that had scored at least 1000 cows.

Of the remaining 19 classifiers, 18 had evaluated at least 1000 first lactation cows. Genetic correlations between BCS from a single classifier and BCS from all other classifiers were generated for those 18 classifiers. The same edits and procedures described below for other analyses were applied. Seventeen of the classifi- ers had genetic correlations for BCS with all other classifiers of greater than 0.90 . One classifier had a genetic correlation for BCS with all other classifiers of 0.75 and data from that classifier was removed.

One classifier had only 137 first lactation records and a genetic correlation between that classifier and all other classifiers could not be estimated, but data from that classifier was not removed. In total, records from 11 of 29 classifiers were eliminated.

Other data edits included a requirement of 20 daughters per sire and 10 cows for each herd-classification visit. Records from cows that had calved before 20 mo of age and after 60 mo of age were eliminated. Records from cows that have calved after 60 mo of age are not used by Holstein Association USA Inc. to generate genetic evaluations for type traits because final score is not allowed to decline after 60 mo of age. Records that were recorded after 305 DIM were also eliminated.

The data edits used here differ from those that would be used for national genetic evaluations. All cows from contemporary groups of two or more are included in national genetic evaluations and no limit is placed on the number of daughters per sire (10 or more daughters are required for an official proof).

An initial data set was formed to determine the effect of editing for classifier on genetic parameter estimates. Unedited traits for BCS, dairy form, stature, strength and final score were formed that included first lactation records from all classifiers if the record was associated with an odd numbered herd-classification date. A second set of edited traits was formed that included first lactation records only from classifiers that were not eliminated by classifier edits and that were associated with even numbered herd-classification date. This data set included 106,257 records that were not edited for classifier and 46,292 records that were edited for classifier.

A data set consisting of 128,478 first lactation cows and a data set consisting of 207,149 cows between the ages of 20 to 60 mo were formed only from records not removed by classifier edits. The cows were sired by 1645 bulls and records were from 11,998 herd-classification visits. Three generations of ancestors were traced for each sire and the final pedigree file included 3156 animals.

\section{Analyses}

All analyses were performed in ASREML (Gilmour et al., 2002) using single to three-trait sire models. Single trait models were used to estimate heritability and repeatability for BCS, dairy form, stature, strength and final score. A series of two-trait sire models were used to estimate correlations among most traits. Three-trait 
sire models were used if the relationship among three traits was of interest. For example, correlation estimates among BCS, foot angle and rear legs side view were generated with a three-trait model, as were correlations among BCS, dairy form and strength in first lactation.

Sire models were chosen because of reduced computational demands, especially for three-trait models, and because data were from a less than three year window which would minimize the number of daughter-dam pairs, especially in the first lactation data. Nearly all pedigree ties in the data are among paternal half-siblings with related sires, and heritability estimates would be expected to be nearly identical to those obtained with an animal model.

Initial analyses were between first lactation records edited for classifier and records not edited for classifier for the following traits: BCS, dairy form, stature, strength and final score.

All other analyses were performed with data that had been edited for classifier. Analyses for first lactation cows only were between BCS and dairy form, and between BCS or dairy form and the following selected type traits: stature, strength, body depth, thurl width, rear legs side view, foot angle, udder composite, frame, feet and legs composite, body size composite, dairy composite and final score.

The final set of analyses were performed with records from all cows calving between 20 and 60 mo of age for the following traits: BCS, dairy form, stature, strength and final score. The set of cows that would be used by the Holstein Association USA Inc. for national genetic evaluations for BCS are most closely represented by this set of analyses.

The statistical model used in the analyses is shown below:

$$
\begin{gathered}
\mathbf{y}_{\mathrm{ijk}}=\mathbf{b}_{1} \times{\text { age }\left(\text { lact }_{\mathrm{i}}\right)}^{6} \\
+\sum_{\mathrm{b}=2} \mathrm{DIM}+\text { Sire }_{\mathrm{j}}+\mathbf{H D} \mathbf{C L}_{\mathrm{k}}+\varepsilon_{\mathrm{ijk}}
\end{gathered}
$$

where

$\mathbf{y}_{\mathrm{ijk}}=$ BCS or a selected type trait for univariate models, a vector of length two for two-trait models, or a vector of length three for three-trait models,

$\mathbf{b}_{1}=\mathbf{a}$ vector of regression coefficients on age at calving nested within lactation,

age $=$ age at calving in months,

lact $_{i}=$ fixed lactation number $\mathrm{i}$,

$\mathbf{b}_{2}$ through $\mathbf{b}_{6}=$ a vector of polynomial regression coefficients of order 1 to 5 on DIM,

$$
\begin{aligned}
\text { DIM }= & \text { days in milk, } \\
\text { Sire }_{j}= & \text { a vector of random effects for sire } \mathrm{j}, \\
\text { HD_CL }_{\mathrm{k}}= & \text { a vector fixed effects for herd-classi- } \\
& \text { fication visit } \mathrm{k},
\end{aligned}
$$

and

$$
\varepsilon_{\mathrm{ijk}}=\text { random error. }
$$

To reduce the number of effects required in the model, cows were not allowed to contribute more than one record in any analyses with one exception; uni-variate models were used to estimate repeatability for BCS, dairy form, stature, strength and final score using records from all cows that had calved from 20 to $60 \mathrm{mo}$ of age. A random, permanent environment effect was included for those analyses. A total of 20,973 cows had more than one record available for this analysis (total number of records $=228,122$ ). For all other analyses, the earliest record was chosen for cows with multiple records within lactation. Likewise, for cows with records from multiple lactations, the earliest lactation with a record was chosen.

The Holstein Association USA Inc. accounts for age and stage of lactation effects by including fixed group effects for age and stage of lactation. This was not done in this study because BCS changes over the lactation period more than other traits, particularly in early lactation. Secondly, average BCS at a given age is affected by the average stage of lactation. Average values for traits like stature would not be expected to increase and decrease with age depending on stage of lactation as would BCS.

\section{RESULTS AND DISCUSSION}

\section{Data Edits}

The polynomial regression solutions for BCS on DIM from the two-trait model of BCS before edits for classifier and BCS after edits for classifier are shown in Figure 1. Regression solutions for BCS decrease from calving until 69 DIM for both traits. There was more change in BCS after edits for classifier. The change from calving to 69 DIM was 2.68 for the unedited data set and 3.42 for the edited data set. The change in BCS from 69 to 305 DIM was 2.97 for the unedited data set and 3.07 for the edited data set. The fixed classes used in the national genetic evaluations to model stage of lactation effects would account for much of the change shown in Figure 1, but solutions would not be as smooth as the curves shown here.

Heritabilities and genetic correlations among records edited and not edited for classifier for BCS, dairy form, stature, strength and final score are shown in Table 1. Genetic correlations between edited and unedited data 


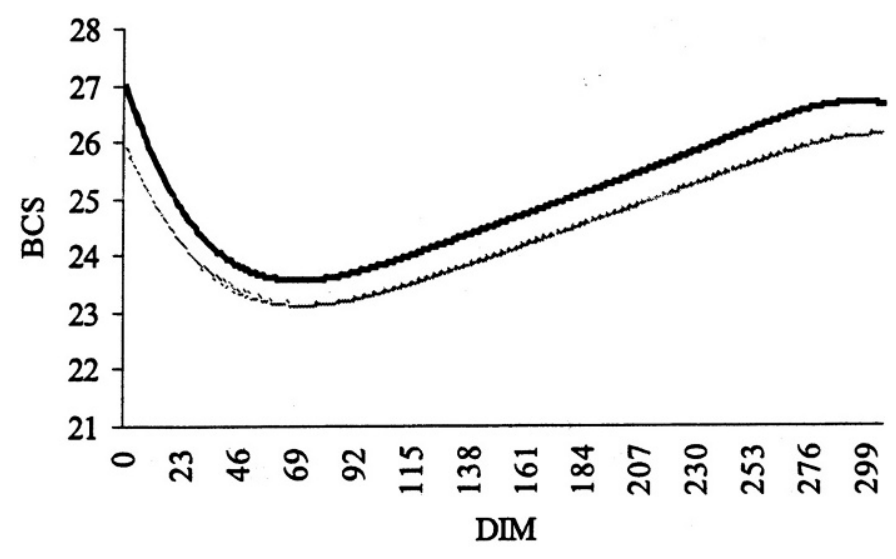

Edited BCS.... Unedited BCS

Figure 1. Regression solutions for BCS on DIM in first lactation before and after edits for classifier.

for all traits were 0.995 or higher. Heritability estimates were highest in the edited data set for all traits. The largest change in heritability estimate was for BCS. The heritability estimate of BCS increased from 0.14 in the unedited data set to 0.19 for the edited data set.

The edits made for classifier appear to have had their intended effect. The high genetic correlation between traits edited and unedited for classifier indicates that classifier edits did not select records from cows that were genetically different for BCS. Thus, the genetic correlation estimates between the BCS records edited for classifier and selected type traits will be accurate. However, the edited data likely had more accurate BCS records, resulting in a higher heritability estimate.

The heritability estimate for BCS reported here is lower than heritability estimates for BCS in first lactation from Europe (Pryce et al., 2000; Koenen et al., 2001; Veerkamp et al., 2001). A sire model was used here, while other reported estimates have been obtained with an animal model or a sire-maternal grandsire model. However, that is not likely the major cause

Table 1. Heritabilities $\left(\mathrm{h}^{2}\right)$ and genetic correlations $\left(\mathrm{r}_{\mathrm{a}}\right)$ between data edited for classifier and data unedited for classifier for body condition score (BCS), dairy form, stature, strength and final score. ${ }^{1}$

\begin{tabular}{llll}
\hline & $\mathrm{h}^{2}$ edited data & $\mathrm{h}^{2}$ unedited data & $\mathrm{r}_{\mathrm{a}}$ \\
\hline BCS & 0.19 & 0.14 & 0.995 \\
Dairy Form & 0.25 & 0.23 & 0.995 \\
Stature & 0.33 & 0.32 & 1.00 \\
Strength & 0.23 & 0.22 & 1.00 \\
Final Score & 0.24 & 0.21 & 1.00 \\
\hline
\end{tabular}

${ }^{1}$ Standard errors for heritability estimates ranged from 0.01 to 0.02. Approximate standard errors for the genetic correlations ranged from 0 to 0.01 . of the lower heritability estimate. The Holstein Association USA Inc. has estimated the heritability of BCS using current national evaluation procedures (which includes an animal model) to be 0.15 using Method $\Re$ (personal communication). Classifiers that gave a large proportion of cows the same BCS were eliminated, but edits were not as stringent as those used in this study.

Other heritability estimates for BCS in the US are lower than heritability estimates for BCS in Europe (Dechow et al., 2001). Body condition scores used in genetic studies in Europe may have been recorded more consistently than those used in genetic studies in the US. The heritability of BCS in the US may increase as classifiers become more accustomed to scoring body condition. It is not clear that management conditions in Europe would result in less environmental variance for BCS, which would also result in higher heritability estimates.

It is possible that the genetic variance for BCS is lower in the US than in Europe. Average BCS was reported to decrease from 5.4 to 4.4 for first lactation Dutch-Friesian cows as the percentage of North American Holstein genes increased from 50 to $100 \%$ (Koenen et al., 2001). A lower average BCS for US dairy cows could be associated with less genetic variance for BCS. Higher yield is genetically correlated with lower BCS (Dechow et al., 2001; Veerkamp et al., 2001). More intense selection for milk yield in the US may have resulted in a lower average BCS and a reduced genetic variance for BCS.

The heritability estimates reported in Table 1 for stature, strength, dairy form and final score are also lower than other estimates published by the Holstein Association USA Inc. (Holstein Association USA Inc., 2002). The estimates reported in Table 1 are for first lactation cows only, however, and estimates that include all lactations are similar to published estimates.

\section{First Lactation Cows}

Correlation estimates between BCS, dairy form and selected type traits in first lactation are reported in Table 2. The genetic correlation estimate between BCS and dairy form was -0.73 while the phenotypic correlation was -0.44 . Genetic correlations between BCS at calving and angularity (similar to US dairy form) in a research herd were reported to range from -0.47 to -0.77 (Veerkamp and Brotherstone, 1997). Cows with high dairy form scores tend to be angular and thin. Body condition score and dairy form are not entirely the same trait, however, and dairy form evaluates more than level of body condition.

There was a strong genetic correlation (0.72) and phenotypic correlation (0.50) between BCS and strength. 
Table 2. Genetic $\left(r_{\mathrm{a}}\right)$ and phenotypic $\left(r_{\mathrm{p}}\right)$ correlation estimates among body condition score (BCS), dairy form, selected linear type traits and final score for first lactation cows. ${ }^{1}$

\begin{tabular}{|c|c|c|c|c|}
\hline & \multicolumn{2}{|c|}{ BCS } & \multicolumn{2}{|c|}{ Dairy Form } \\
\hline & $\left(r_{a}\right)$ & $\left(r_{p}\right)$ & $\left(r_{a}\right)$ & $\left(r_{p}\right)$ \\
\hline Dairy Form & -0.73 & -0.44 & 1.00 & 1.00 \\
\hline Strength & 0.72 & 0.50 & -0.16 & -0.02 \\
\hline Stature & 0.20 & 0.19 & 0.23 & 0.19 \\
\hline Body Depth & 0.40 & 0.34 & 0.20 & 0.23 \\
\hline Thurl Width & 0.27 & 0.22 & 0.16 & 0.12 \\
\hline Body Size Composite & 0.43 & 0.36 & 0.18 & 0.19 \\
\hline Frame & 0.25 & 0.21 & 0.24 & 0.26 \\
\hline Rear Legs Side View & -0.38 & -0.19 & 0.35 & 0.11 \\
\hline Foot Angle & 0.38 & 0.18 & -0.21 & 0.01 \\
\hline Feet and Legs Composite & 0.19 & 0.14 & -0.03 & 0.10 \\
\hline Dairy Composite & -0.75 & -0.46 & 0.93 & 0.84 \\
\hline Udder Composite & 0.10 & 0.03 & 0.10 & 0.18 \\
\hline Final Score & 0.05 & 0.05 & 0.34 & 0.41 \\
\hline
\end{tabular}

${ }^{1}$ Standard errors for genetic correlation estimates ranged from 0.007 to 0.055 , while standard errors for phenotypic correlation estimates ranged from 0.001 to 0.004 .

Others have reported moderate to strong genetic correlation estimates between BCS and measures similar to strength. Genetic correlation estimates between BCS and chest width ranged from 0.32 to 0.73 , whereas the genetic correlation between BCS and heart girth circumference was reported to be 0.34 (Veerkamp and Brotherstone, 1997; Gallo et al., 2001). Additionally, dairy character had a negative genetic correlation $(-0.47)$ with muscularity (Koenen and Groen, 1998). Genetic correlations between BCS and muscularity would thus be expected to be positive.

BCS was also positively correlated with body size composite and other body dimension traits including stature, body depth, frame and thurl width both genetically (range 0.20 to 0.43 ) and phenotypically (range 0.19 to 0.36). Genetic correlation estimates between BCS and stature were reported to range from -0.09 to 0.32 (Veerkamp and Brotherstone, 1997). Negative genetic correlation estimates were reported for first lactation cows only and were positive for cows of all ages. Genetic correlation estimates between BCS and body depth ranged from -0.24 to 0.26 in the same study, with negative correlations occurring in first lactation cows only. Veerkamp and Brotherstone (1997) reported the genetic correlation between BCS and live weight to be 0.67, while Enevoldsen et al. (1997) reported the phenotypic correlation between BCS and BW to be 0.53. Cows with more body condition have more body fat and muscle, and thus appear to be stronger, have somewhat larger body dimensions and weigh more.

The genetic correlation estimate between dairy form and strength was -0.16 , while the phenotypic correlation was -0.02 . Genetic and phenotypic correlation estimates between dairy form and body size composite and other body dimension traits were positive, ranging from 0.12 to 0.26 .
Genetic correlation estimates between dairy character and measures of body size, including heart girth, hip height, body depth, size and rump width, were reported to range from 0.14 to 0.70 , whereas phenotypic correlations ranged from 0.08 to 0.61 (Koenen and Groen, 1998). Dairy character was reported to be positively correlated with BW both genetically $(0.15)$ and phenotypically (0.11) in the same study. Veerkamp and Brotherstone (1997) reported negative genetic correlations (range -0.07 to -0.56 ) between angularity and live weight however.

Cows with high dairy form scores likely have larger body dimensions, but the relationship between dairy form and BW is less clear because cows with higher dairy form are also thinner. Cows with higher dairy form also appear to have slightly lower strength scores and may have less muscularity.

Genetic correlation estimates between BCS and feet and legs composite, foot angle and rear legs side view were $0.19,0.38$, and -0.38 , respectively. Phenotypic correlation estimates were $0.14,0.18$, and -0.19 between BCS and feet and legs composite, foot angle and rear legs side view, respectively. The genetic and phenotypic correlation estimates between dairy form and feet and legs composite were -0.03 and 0.10 , respectively, -0.21 and 0.01 between dairy form and foot angle, and 0.35 and 0.11 between dairy form and rear legs side view.

Cows with higher BCS would be expected to be heavier and heavier cows have more foot and leg trouble than smaller cows. Cows that have been selected for higher body size weighed $51 \mathrm{~kg}$ more after calving than herd mates selected for smaller body size in an experimental herd in Minnesota (Hansen et al., 1999). The cows selected for larger body size were culled more often for leg and foot problems than cows that were selected for small body size. The authors speculated that the 
Table 3. Genetic variance $\left(V_{\mathrm{a}}\right)$, permanent environmental variance $\left(\mathrm{V}_{\mathrm{pe}}\right)$, residual variance $\left(\mathrm{V}_{\mathrm{e}}\right)$, heritability $\left(\mathrm{h}^{2}\right)$ and repeatability (rpt) for body condition score (BCS), dairy form, selected linear type traits and final score for all cows ages 20 to 60 mo. ${ }^{1}$

\begin{tabular}{lccccc}
\hline & $\left(\mathrm{V}_{\mathrm{a}}\right)$ & $\left(\mathrm{V}_{\mathrm{pe}}\right)$ & $\left(\mathrm{V}_{\mathrm{e}}\right)$ & $\mathrm{h}^{2}$ & $\mathrm{rpt}$ \\
\hline BCS & 7.16 & 3.77 & 22.18 & 0.22 & 0.33 \\
Dairy Form & 10.16 & 15.6 & 16.47 & 0.24 & 0.61 \\
Stature & 18.84 & 13.91 & 18.30 & 0.37 & 0.64 \\
Strength & 10.8 & 8.98 & 20.80 & 0.27 & 0.49 \\
Final Score & 5.12 & 12.65 & 2.95 & 0.25 & 0.85 \\
\hline
\end{tabular}

${ }^{1}$ Standard errors for heritability and repeatability estimates ranged from 0.01 to 0.02 .

higher BW of the larger cows resulted in greater stress on the cow's feet and legs and the larger cows may have been more prone to foot and leg injuries. However, cows with lower BCS (and are thus likely to weigh less) had slightly lower feet and legs composite, a lower foot angle and more set to the hock in this study.

Cows that were genetically inclined to have higher dairy form scores also had more set to the hock and had slightly lower foot angles. Moreover, Rogers et al. (1999) reported that sires with daughters that had high dairy form also had daughters with poorer foot and leg health. Cows that are thin appear to have more set to the hock, a lower foot angle and poorer foot and leg health despite likely having a lower BW. Perhaps cows that are inclined to be thin and angular are susceptible to more stress on their feet and legs. Poor locomotion could also reduce BCS because of reduced feed intake. The relationship between BW and foot and leg conformation or foot and leg health might be even more apparent if BCS or dairy form is considered in the model.

The genetic and phenotypic correlation estimates between BCS and final score were 0.05. The genetic and phenotypic correlation estimates between dairy form and final score were 0.34 and 0.41 , respectively. Despite the strong genetic correlation between BCS and dairy form, BCS is not included in calculation of final score and is therefore more independent of final score than is dairy form.

\section{All Cows}

Heritabilities, repeatabilities, and variances for BCS, dairy form, stature, strength and final score for all cows are in Table 3. Heritability estimates were lowest for BCS (0.22) and highest for stature (0.37). The heritability estimates for all traits, except dairy form (0.24), were higher for all cows than for first lactation cows only. Heritability estimates for stature and dairy form reported previously using a sire-maternal grandsire model were identical to those reported here, whereas the heritability estimate for strength was 0.29 (Short et al., 1991). The heritability estimates are slightly lower than those obtained using an animal model. Heritability estimates using an animal model have been reported to range from 0.41 to 0.42 for stature, 0.29 to 0.30 for strength, and were reported to be 0.28 for dairy form and 0.29 for final score (Misztal et al., 1992; Misztal et al., 1995).

Repeatability estimates ranged from 0.33 for BCS to 0.85 for final score. Repeatability estimates obtained using an animal model are nearly identical to those for stature and strength, but lower (0.46) for dairy form (Misztal et al., 1995).

Genetic and phenotypic correlations among BCS, dairy form, stature, strength and final score for all cows are reported in Table 4. Genetic and phenotypic correlation estimates between BCS and dairy form and stature, strength and final score were similar to those reported for first lactation cows only. The genetic correlation estimate between final score and BCS (0.08) was lower than genetic correlation estimates between final score and dairy form, stature and strength (range 0.34 to 0.56). Phenotypic correlations between final score and BCS $(0.06)$ were also lower than phenotypic correlation estimates between final score and dairy form, stature and strength (range 0.36 to 0.41 ).

Table 4. Genetic (above diagonal) and phenotypic (below diagonal) correlation estimates among body condition score (BCS), dairy form, selected linear type traits and final score for all cows ages 20 to 60 mo. ${ }^{1}$

\begin{tabular}{lcllcl}
\hline & BCS & Dairy Form & Stature & Strength & Final Score \\
\hline BCS & & -0.72 & 0.27 & 0.69 & 0.08 \\
Dairy Form & -0.44 & & 0.21 & -0.11 & 0.34 \\
Stature & 0.20 & 0.19 & & 0.73 & 0.56 \\
Strength & 0.49 & 0.00 & 0.57 & & 0.42 \\
Final Score & 0.06 & 0.41 & 0.36 & 0.32 & \\
\hline
\end{tabular}

${ }^{1}$ Standard errors for the genetic correlation estimates ranged from 0.02 to 0.04 , while standard errors for the phenotypic correlation estimates ranged from 0.002 to 0.003 . 
Genetic and phenotypic correlation estimates previously reported among dairy form, stature and strength are similar to those reported in this study (Misztal et al., 1992). Previously reported genetic correlations between final score and stature (0.75) and strength (0.62) were somewhat higher than reported in this study (Misztal et al., 1992).

\section{CONCLUSIONS}

Body condition scores routinely recorded by Holstein Association USA Inc. provide an extensive and consistent source of BCS observations. The editing and evaluation procedures used in this study differ than those used currently for national evaluations and the parameter estimates used in a national genetic evaluation might vary slightly from those reported here. The heritability estimate of BCS is expected to increase as classifiers become more accustomed to evaluating cows for BCS, however. Body condition score is highly correlated with dairy form and strength. BCS is not highly correlated with final score and BCS evaluations may be influenced less by final score than many type traits. Previously reported relationships between BCS and reproductive performance coupled with heritable variation for BCS may warrant generation of national BCS evaluations. Body condition score evaluations would likely be useful as an early indicator of reproductive fitness.

\section{ACKNOWLEDGMENTS}

Appreciation is expressed to the Holstein Association USA Inc. for providing data and financial assistance, and to the National Milk Producers Federation for providing financial assistance.

\section{REFERENCES}

Dechow, C. D., G. W. Rogers, and J. S. Clay. 2001. Heritabilities and correlations among body condition scores, production traits, and reproductive performance. J. Dairy Sci. 84:266-275.
Enevoldsen, C., and T. Kristensen. 1997. Estimation of body weight from body size measurements and body condition scores in dairy cows. J. Dairy Sci. 80:1988-1995.

Gallo, L., P. Carnier, M. Cassandro, R. Dal Zotto, and G. Bittante. 2001. Test-day genetic analysis of condition score and heart girth in Holstein Friesian cows. J. Dairy Sci 84:2321-2326.

Gilmour, A.R., B. R. Cullis, S.J. Welham, and R. Thompson. 2002. ASREML Reference Manual. ftp:ftp.res.bbsrc.ac.uk/pub/aar.

Hansen, L. B., J. B. Cole, G. D. Marx, and A. J. Seykora. 1999. Productive life and reasons for disposal of Holstein cows selected for large versus small body size. J. Dairy Sci. 82:795-801.

Hansen, M., M. S. Lund, M. K. Sorensen, and L. G. Christensen. 2002. Genetic parameters of dairy character, protein yield, clinical mastitis, and other diseases in the Danish Holstein cattle. J. Dairy Sci. 85:445-452.

Holstein Association USA Inc. 2002. Sire Summaries. August 2002.

Koenen, E. P. C., and A. F. Groen. 1998. Genetic evaluation of body weight of lactating Holstein heifers using body measurements and conformation traits. J. Dairy Sci. 81:1709-1713.

Koenen, E. P. C., R. F. Veerkamp, P. Dobbelaar, and G. De Jong. 2001. Genetic analysis of body condition score of lactating Dutch Holstein and Red-and-White heifers. J. Dairy Sci. 84:1265-1270.

Misztal, I., T. J. Lawlor, T. H. Short, and P. M. VanRaden. 1992. Multiple-trait estimation of variance components of yield and type traits using an animal model. J. Dairy Sci. 75:544-551.

Misztal, I., K. Weigel, and T. J. Lawlor. 1995. Approximation of estimates of (co)variance components with multiple-trait restricted maximum likelihood by multiple diagonalization for more than one random effect. J. Dairy Sci. 78:1862-1872.

Pryce, J. E., M. P. Coffey, and S. Brotherstone. 2000. The genetic relationship between calving interval, body condition score and linear type and management traits in registered Holsteins. J. Dairy Sci. 83:2664-2671.

Rogers, G. W., G. Banos, and U. Sander-Nielsen. 1999. Genetic correlations among protein yield, productive life, and type traits from the United States and diseases other than mastitis from Denmark and Sweden. J. Dairy Sci. 82:1331-1338.

Short, T. H., T. J. Lawlor, and K. L. Lee. 1991. Genetic parameters for three experimental linear type traits. J. Dairy Sci. 74:2020-2025.

Veerkamp, R. F., and S. Brotherstone. 1997. Genetic Correlations between linear type traits, food intake, live weight and condition score in Holstein Friesian dairy cattle. Anim. Sci. 64:385-392.

Veerkamp, R. F., C. L. Gerritsen, E. P. C. Koenen, A. Hamoen, and G. De Jong. 2002. Evaluation of classifiers that score linear type traits and body condition score using common sires. J. Dairy Sci. 85:976-983.

Veerkamp, R. F., E. P. C. Koenen, and G. De Jong. 2001. Genetic correlations among body condition score, yield, and fertility in first-parity cows estimated by random regression models. J. Dairy Sci. 84:2327-2335. 